American Journal of Applied Sciences 5 (5): 532-539, 2008

ISSN 1546-9239

(C) 2008 Science Publications

\title{
Computational Visualization and Simulation of Diesel Engines Valve Lift Performance Using CFD
}

\author{
${ }^{1}$ Semin, ${ }^{1}$ Rosli Abu Bakar and ${ }^{1}$ Abdul Rahim Ismail \\ ${ }^{1}$ Automotive Focus Group, Faculty of Mechanical Engineering, \\ University Malaysia Pahang, Locked Bag 12, 25000 Kuantan, Pahang, Malaysia
}

\begin{abstract}
The paper visualized and simulated the intake and exhaust valve lift in the single-cylinder four-stroke direct injection diesel engine. The visualization and simulation computational development were using the commercial Computational Fluid Dynamics of STAR-CD 3.15A software and GTSUITE 6.2 software. The one dimensional of valve lift modeling was developed using GT-POWER software and the visualization the model using STAR-CD. The model simulation covers the full engine cycle consisting of intake, compression, power and exhaust. The visualization and simulation shown the diesel engine intake and exhaust valve lifting and moving based on the crank angle degree parameters. The result of this visualization and simulation shows the intake and exhaust valve lift moving and air fluid flow of the diesel engine model.
\end{abstract}

Keywords: Computational simulation, diesel engine performance, fuel nozzle multi holes

\section{INTRODUCTION}

In this paper a four-stroke direct-injection diesel engine typical was measured. The data from the engine measurements are use for modeling and visualization the diesel engine model in this paper. The GT-POWER computational model shows one-cylinder diesel engine intake and exhaust valve lift simulation performance. Gamma Technologies ${ }^{[2]}$ was written that GT-POWER is the leading engine simulation tool used by engine and vehicle makers and suppliers and is suitable for analysis of a wide range of engine issues. The visualization of the diesel engine intake and exhaust valve lift and moving are using STAR-CD ${ }^{[13]}$.

According to Heywood ${ }^{[1]}$ and Ganesan ${ }^{[10]}$ a wide variety of inlet port geometries, cylinder head and piston shapes, and fuel-injection patterns are used to accomplish this over the diesel size range. The diesel engine typical was measured and modeling by Bakar ${ }^{[7]}$ using GT-POWER computational model and explored of single-cylinder diesel engine performance effect based on engine rpm. In this paper focused in the intake valve lift and exhaust valve lift performance.

\section{MATERIALS AND METHODS}

The visualization and simulation development of single cylinder modeling and simulation for four-stroke direct-injection (DI) diesel engine was presented in this paper. The specification of the selected diesel engine shows in Table 1.

Table 1: Specification of the selected diesel engine

\begin{tabular}{ll}
\hline Engine Parameters & Value \\
\hline Bore $(\mathrm{mm})$ & 86.0 \\
Stroke $(\mathrm{mm})$ & 70.0 \\
Displacement $(\mathrm{cc})$ & 407.0 \\
Number of cylinder & 1 \\
Connecting rod length $(\mathrm{mm})$ & 118.1 \\
Piston pin offset $(\mathrm{mm})$ & 1.00 \\
Intake valve open $\left({ }^{0} \mathrm{CA}\right)$ & 395 \\
Intake valve close $\left({ }^{0} \mathrm{CA}\right)$ & 530 \\
Exhaust valve open $\left({ }^{0} \mathrm{CA}\right)$ & 147 \\
Exhaust valve close $\left({ }^{0} \mathrm{CA}\right)$ & 282 \\
Maximum intake valve open $(\mathrm{mm})$ & 7.095 \\
Maximum exhaust valve open $(\mathrm{mm})$ & 7.095 \\
Valve lift periodicity $(\mathrm{deg})$ & 360 \\
Fuel nozzle diameter $(\mathrm{mm})$ & 0.1 \\
Fuel nozzle hole number $(\mathrm{pc})$ & 4 \\
\hline
\end{tabular}

Valve Lift Visualization Using STAR-CD: The mass and momentum conservation equations solved by STAR-CD for general incompressible and compressible fluid flows and a moving coordinate frame the Navier Stokes equations are, in Cartesian tensor ${ }^{[1]}$.

Corresponding Author: Semin, Automotive Focus Group, Faculty of Mechanical Engineering, University Malaysia Pahang, Locked Bag 12, MEC City Gambang, 25000 Kuantan, Pahang, Malaysia, Tel: +6095492217, Fax: +609-5492244 


$$
\begin{aligned}
& \frac{1}{\sqrt{g}} \frac{\partial}{\partial t}(\sqrt{g} \rho)+\frac{\partial}{\partial x_{j}}\left(\rho \bar{u}_{j}\right)=s_{m} \\
& \frac{1}{\sqrt{g}} \frac{\partial}{\partial t}\left(\sqrt{g} \rho u_{i}\right)+\frac{\partial}{\partial x_{j}}\left(\rho \bar{u}_{j} u_{i}-\tau_{i j}\right)=-\frac{\partial p}{\partial x_{i}}+s_{i}
\end{aligned}
$$

where $t$ is time, $x_{i}$ is cartesian coordinate $(i=1,2,3), u_{i}$ is absolute fluid velocity component in direction, $\tilde{u}_{j}$ is $u_{j^{-}} u_{c j}$ relative velocity between fluid and local (moving) coordinate frame that moves with velocity $u_{c j}$, $\rho$ is density, $\tau_{i j}$ is stress tensor components, $s_{m}$ is mass source, $s_{i}$ is momentum source components, $\sqrt{ } g$ is determinant of metric tensor.

$p=p_{s}-\rho_{0} \cdot g_{m} \cdot x_{m}$

where $p$ is piezometric pressure, $p_{s}$ where is static pressure, $\rho_{0}$ is reference density, the $g_{m}$ are gravitational field components and the $x_{m}$ are coordinates from a datum, $\rho_{0}$ where is defined.

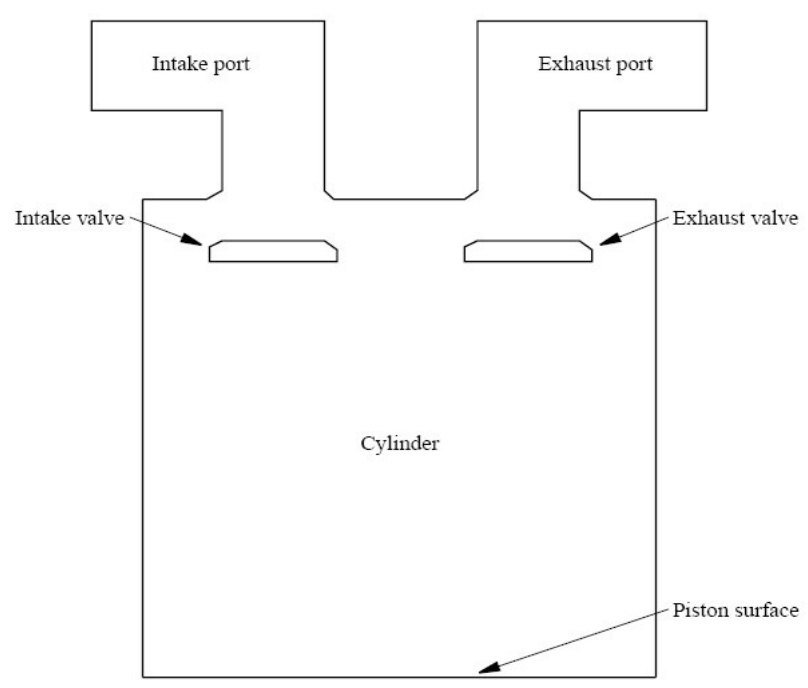

Fig. 1: Engine cylinder intake $\&$ exhaust valves ${ }^{[1]}$

This specialization of the above equations to a particular class of flow involves for application of ensemble or time averaging if the flow is turbulent, specification of a constitutive relation connecting the components of the stress tensor to the velocity gradients and specification of the source, which represents the sum of the body and other external forces, if present.

The fluid in the cylinder is assumed to be air, behaving as an ideal gas. Constant, zero-pressure boundary conditions are assigned at the intake and exhaust port ends. The fluid originally in the intake port is assumed to be a different species called intake with the properties of air. Similarly, the exhaust port is filled with another fluid species called exhaust. The boundary concentrations for the two species are also set appropriately. By tracking the concentration of these species, the fresh charge and exhaust gas distributions can be deduced and global parameters such as volumetric efficiency, etc. can be computed. It should be noted that the model used in this tutorial is too coarse for any realistic computation of these values. The valve lifts follow the curves shown in Figure 2. In this model the exhaust valve opens within the first $147^{0}$ and closes linearly by $282^{\circ}$. The intake valve begins to open at $395^{\circ}$ and closes by $530^{\circ}$. Although this is a very simplistic profile, the technique used here to define valve lift is quite general and can be used for any lift profile. The piston motion is prescribed by setting the standard kinematic parameters for the connecting rod length, the crank radius and the top dead centre position.

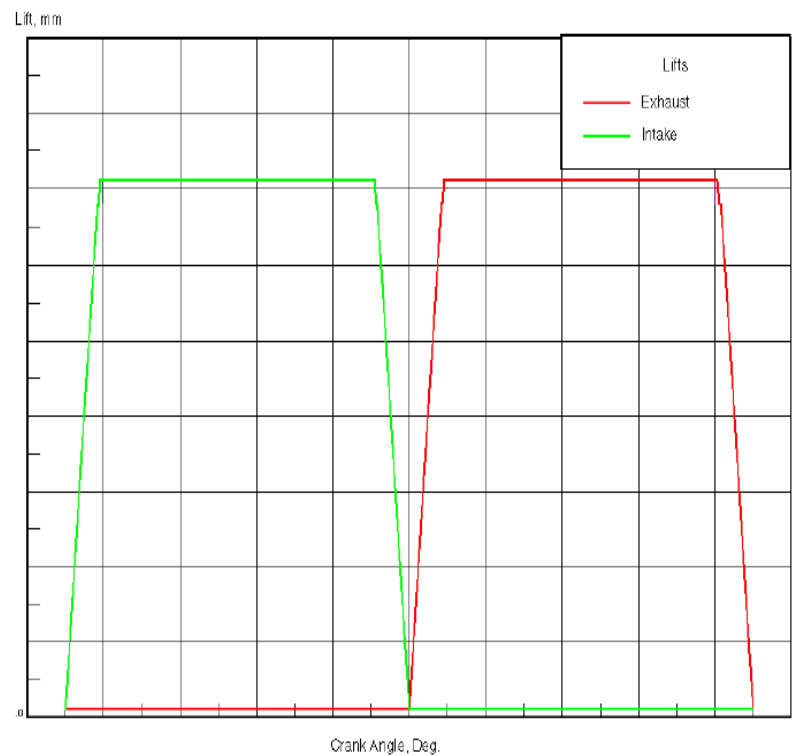

Fig. 2: Valve lift profile

In this visualization models the engine operation during exhaust and intake strokes. It is made up of three parts. The first is prostar pre-processing, including the problem setup, grid-changing commands and event verification. The second is star analysis, including the PMOV pre-processing. The third is prostar postprocessing, including visualization and animated display of the valve moving transients. The simulation start from the intake port, intake valve, engine cylinder, piston motion, exhaust valve and exhaust port. 
Valve Lift Simulation Using GT-POWER: To develop the GT-POWER modeling of the intake and exhaust valve lift of the engine, the first step is open the selected diesel engine to measure the engine components size. Then, the engine components size data will be input to the GT-POWER library of the all engine components data. To Create the GT-POWER model, select Window and then Tile With Template Library from the menu. This will place the GT-POWER template library on the left hand side of the screen. The template library contains all of the available templates that can be used in GT-POWER. Some of these templates (those that will be needed in the project) need to be copied into the project before they can be used to create objects and parts. For the purpose of this model, click on the icons listed and drag them from the template library into the project library. Some of these are templates and some are objects that have already been defined and included in the GT-POWER template library.

In this model the engine was breakdown to the tree system, there are intake system, engine cylinder and fuel injection system, and exhaust system. In the selected diesel engine, the intake system its have any component, size and different data. The system was started from environment till the intake valve. All of the intake system components in the GT-POWER model are environment, intrunnerairfilter, air filter, intrunner, inport, intvalve. Every components in this system they need any data to complete the data form and running the model. The engine cylinder and fuel injection system is focused in engine cylinder performance were support diesel fuel from fuel injection system, fresh air intake system and exhaust gas to exhaust system. There are any components in the engine cylinder and fuel injection system in the diesel engine, but the basic for all diesel engines is the same component. The components, size and data must be record and inserted to the GT-POWER form. All of the engine cylinder and fuel injection system component are injector, cylinder and engine. Every components in this system they need any data to complete the data form and running the model. The last system in the diesel engine is the exhaust system. In this system was started from exhaust valve and finished in the environment. The GTPOWER components in the exhaust system are exhvalve, exhport, exhrunner, muffler, exhrunnerexit, and environment. Every components in this system they need any data to complete the data form and running the model. After finished the every system model in the diesel engine system developed, its can to develop the diesel engine modeling using GT-POWER model. The diesel engine modeling using GT-POWER computational model, there are the intake system model, engine cylinder and fuel injection system model, and exhaust system model. The intake system and the engine cylinder and fuel injection system were connected in the intvalve in the intake system and cylinder in the engine cylinder and fuel injection system. The engine cylinder and fuel injection system connected to the exhaust system in the cylinder in the engine cylinder and fuel injection system with exhvalve in the exhaust, shown in Figure 3. All of this diesel engine components connected by orifficeconn. If the work was finish its can developed the diesel engine modeling using GT-POWER software. The Figure 3 shows the diesel engine modeling using GT-POWER modeling.

Data needed for building an engine model. A list of information that is needed to build a model in GTPOWER is included in library. Not every item will be needed for all models, and sometimes additional information will be needed, but the list is generally a good starting point. If the model is being built at an early design stage, determining optimal values for some of the items listed may be the purpose of the simulation. If this is the case, those particular attributes should be defined as parameters and run for a series of cases to determine an optimal value. Data in engine characteristics are compression ratio, firing order, inline or V configuration, V-angle (optional), 2 or 4 stroke. Data in cylinder geometry are bore, stroke, connecting rod length, pin offset, piston TDC clearance height, head bowl geometry, piston area and head area.

Data in intake and exhaust system is geometry of all components. Data in throttles are throttle location and discharge coefficients versus throttle angle in both flow directions. Data in fuel injectors are location and number of injectors, number of nozzle holes and nozzle diameter, injection rate, fuel type and LHV. Data in intake and exhaust valves are diameter of valve, lift profile, discharge coefficient, valve lash. Data in ambient state are pressure, temperature and humidity. Performance data can be very useful when tuning a model after it has been built.

Before running the model the preparing to run the model simulation needed. Preparing to run the model simulation are review the completed model, run setup, case setup, plot requests and plot setup. All of the parameters in the model will be listed automatically in the case setup and each one must be defined for first case of the simulation. Frequently, computation time can be reduced in steady state simulations by planning the order of the simulations and utilizing the 
initialization state in run setup. Cycle and/or time plots may be requested by selecting the appropriate plot from the plot options folder within each part. All plots requested in individual parts will be stored regardless of whether the user chooses to use plot setup. If the model has been prepared for simulation, the GT-POWER simulation may be started and this will start the simulation running. A window will be progress of simulation in the form of scrolling text. Once the input has been read successfully, the simulations will begin, and occasional reports of the progress will be given.

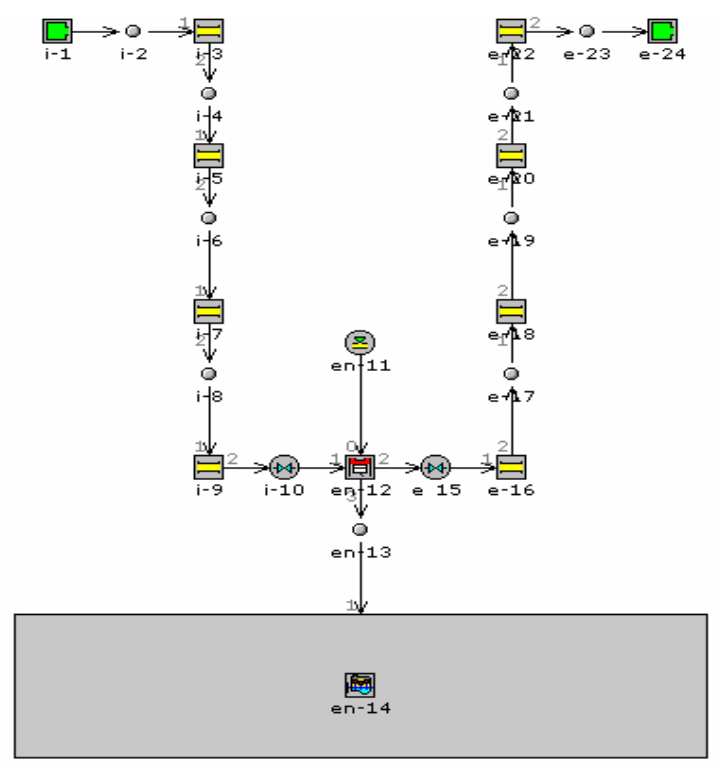

Fig. 3: Diesel engine model using GT-POWER

\section{RESULTS AND DISCUSSION}

Valve Lift Visualization: Mesh design in problems with a moving mesh and changing cell connectivity is dominated by the need to keep the dynamic parts of the grid simple so that they can be easily changed during the transient run. The formulation of mesh motion in such problems is divided into two conceptual steps. The first deals with connectivity changes cell removal, addition, reconnection, etc., which are defined by PROSTAR events. The second step is to specify the grid vertex positions as a function of time by supplying a set of PROSTAR grid-manipulation commands to be executed at each time step.

Other considerations include three strategies. The first is the initial mesh must contain all the cells that will be used in the analysis. Thus, it will be seen that the initial grid construction contains overlapping cells in the vicinity of the valves. These cells are rearranged according to the valve position at time $=0.0$, i.e. at the start of the calculations. The second is when cells are added or activated, they are still deemed to be connected to the neighbours they had at the time of their removal or deactivation. This imposes sequencing constraints on the activation and deactivation processes. The third is if any part of the solution domain becomes separated from the rest of the flow field during a transient run (e.g. the intake port after the intake valve has closed) the cell material type in that domain must be changed. All material types used must have been defined in the initial setup.

The intake and exhaust stroke flow simulation in an engine cylinder illustrates some of the transient, dynamic-mesh features, event handling, moving grids and cell attachment/detachment by setting up and solving a simplified port-valve and piston problem using STAR-CD computational fluid dynamics. The problem is two-dimensional and represents a simplified four-stroke engine. The simulation commences at bottom dead centre (BDC) and continues for a time interval corresponding to $360^{\circ}$ of crank revolution. Inert scalars with the physical properties of air are used to track the intake and exhaust stream through the exhaust induction strokes in engine cylinder. The flow in engine cylinder is turbulent and driven entirely by the motion of the piston and valves. The port boundary pressures are held constant at ambient condition throughout the simulation. Mesh design in problems with a moving mesh and changing cell connectivity is dominated by the need to keep the dynamic parts of the grid simple so that they can be easily changed during the transient run. The formulation of mesh motion in such problems is divided into two conceptual steps. The first deals with connectivity changed which are defined by PROSTAR events. The second step is to specify the grid vertex positions as function of time by supplying a set of PROSTAR grid-manipulation commands to be executed at each time step. In this model the exhaust valve opens within the first $147^{\circ}$ of crank angle until $282^{0}$ of crank angle ${ }^{0}$. The intake valve begins to open at $395^{\circ}$ of crank angle and close until $530^{\circ}$ of crank angle. The piston motion is prescribed by setting the standard kinematics parameters for the connecting rod length, the crank radius and the top dead centre position. 
Am. J. Applied Sci., 5 (5): 532-539, 2008

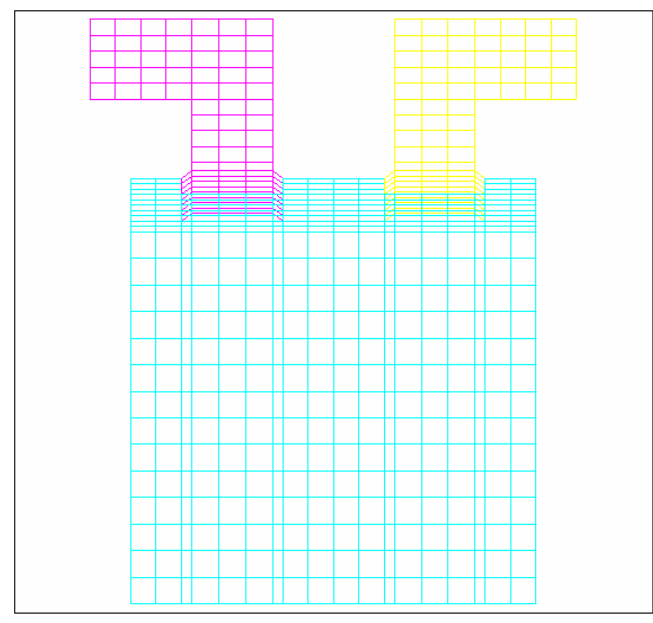

Fig. 4: Mesh definition of model

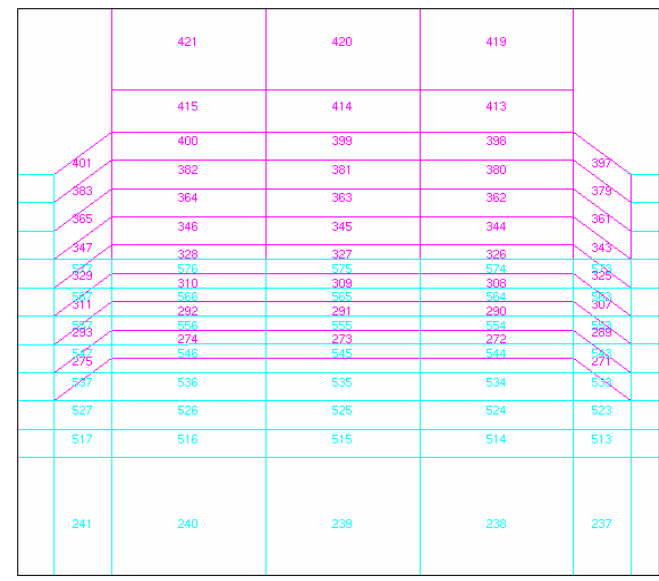

Fig. 5: Boundary condition of model

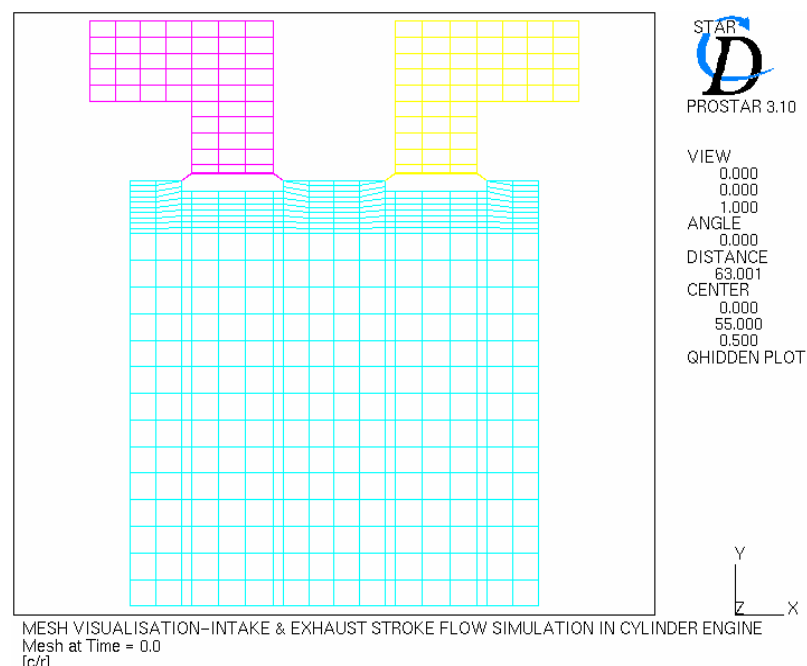

Fig. 6: Mesh visualization at time 0.0
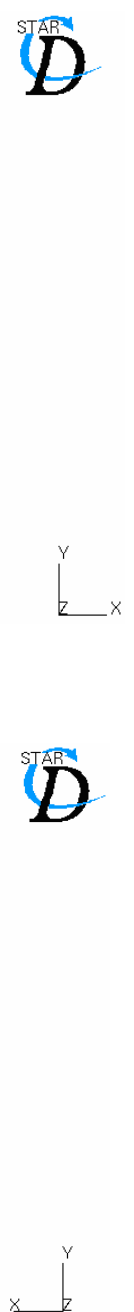

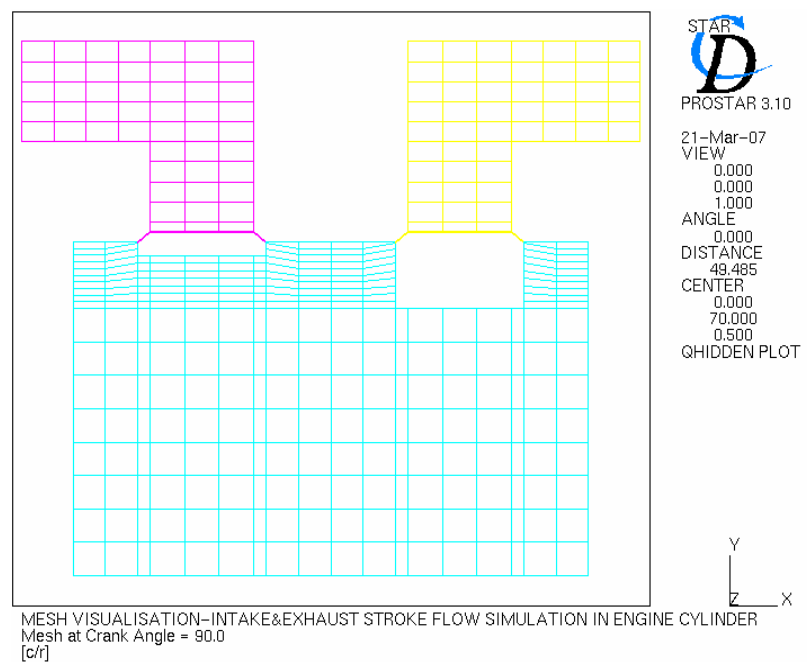

Fig. 7: Mesh visualization at crank angle 90.0

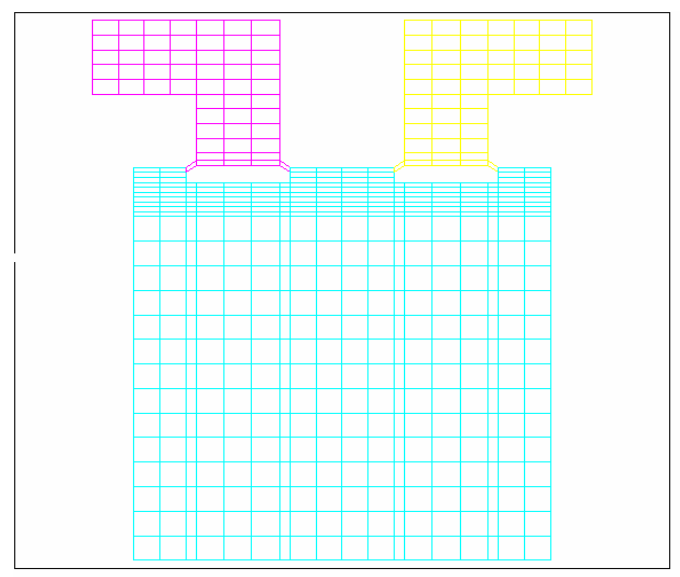

D

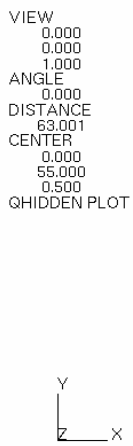

Fig. 8: Mesh animation at crank angle degree 1.0
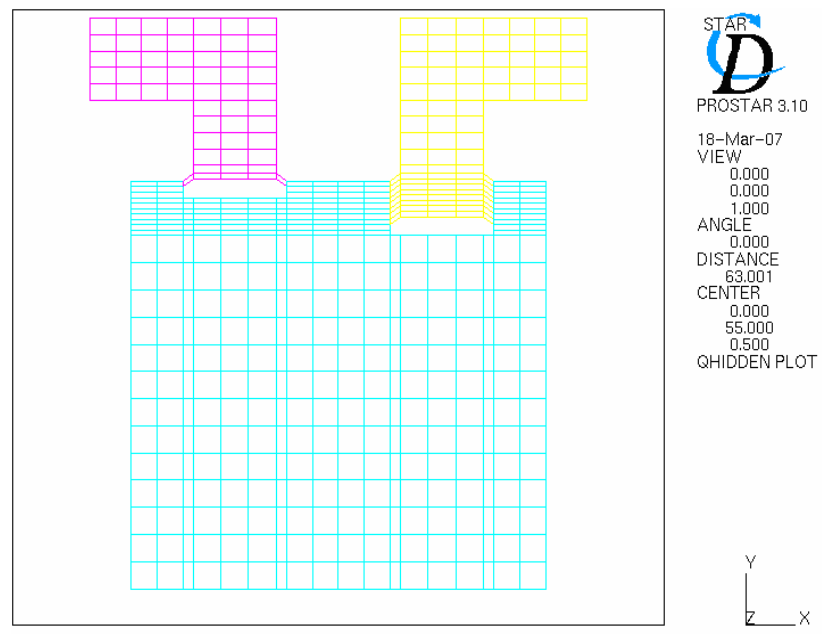

Fig. 9: Mesh animation at crank angle degree 40.0 

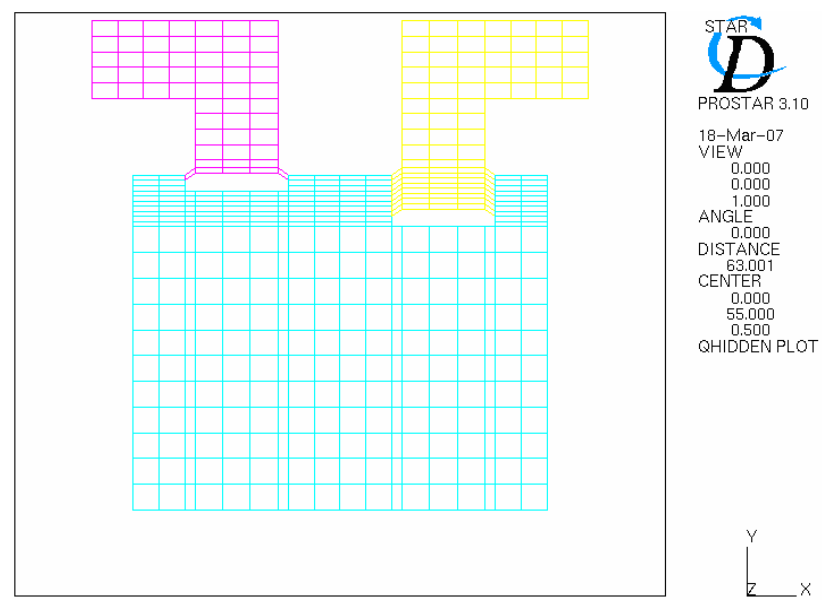

Fig. 10: Mesh animation at crank angle degree 60.0
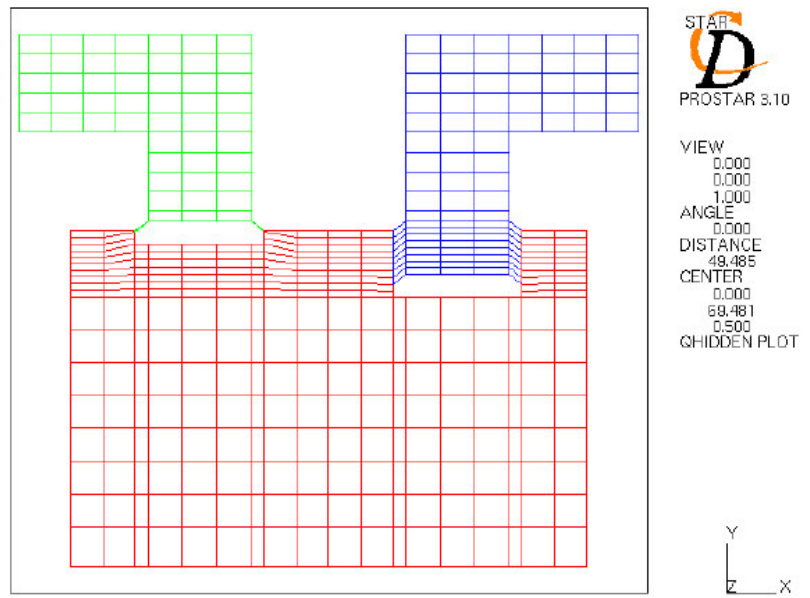

Fig. 11: Mesh animation at crank angle degree 90.0

In the intake valve events, were defining of the intake valve events, the natural choice for specifying the occurrence of these events would be the crank angle using command EVPARM. The reason EVPARM is respecified is because it allows you to use a convenient initial angle which does not have to match the initial position of the piston. EVPARM, DEGREES, 1000, 0.0 . The mesh at the intake valve at time $\mathrm{t}=0$ must first be rearranged, i.e. the extra, overlapping cells in that region must be deactivated. Seven cell layers above the valve must be deactivated before the solution starts (the valve is initially closed). This must be done in the correct sequence. For this reason, negative event times are used to establish the sequence of deactivation events that occur before the flow field computation begins. At time $t=0$, the side faces of the surviving cells below the valve must be connected together. This is done with an attachment event at time $t=0$. Since event times must be unique, we have to reuse event no. 40 which is already set to occur at this time. The cell faces to be attached are found automatically using the EAMATCH command. For this, we need to group the faces to be matched into two regions. The attachment boundaries belonging to the cylinder have already been assigned to region no. 1; the attachment boundaries belonging to the valve that need to be matched to the cylinder boundaries must be collected and temporarily assigned to region no. 3. The boundary sets to be matched are nominally unequal because of the presence of deactivated cell layers. Nevertheless, the operation is physically valid and also avoids the trouble of picking out the right faces. EAMATCH will generate

warning messages which should be ignored. No further intake valve events occur until the crank angle is $180^{\circ}$. At this time, the layer above the valve should be connected to the cylinder. This also means that the cells in the inlet port must be changed to the material type of the cylinder, as they are now physically connected to it. As the valve opens between $180^{\circ}$ and $200^{\circ}$, seven cell layers are deactivated below the valve and corresponding cell layers activated above the valve. The side connections between cell layers are also altered to match the new configuration. The final event at $360^{\circ}$ will completely close the valve by detaching the last connection (in the layer above the valve) and changing the material type of the cells trapped above the valve.

In the exhaust valve events, a similar sequence of events occurs for the exhaust valve. Note, however, that the opening and closing times are different. Reuse event nos. 30 to 36 for deactivating overlapping cell layers prior to time $\mathrm{t}=0$.

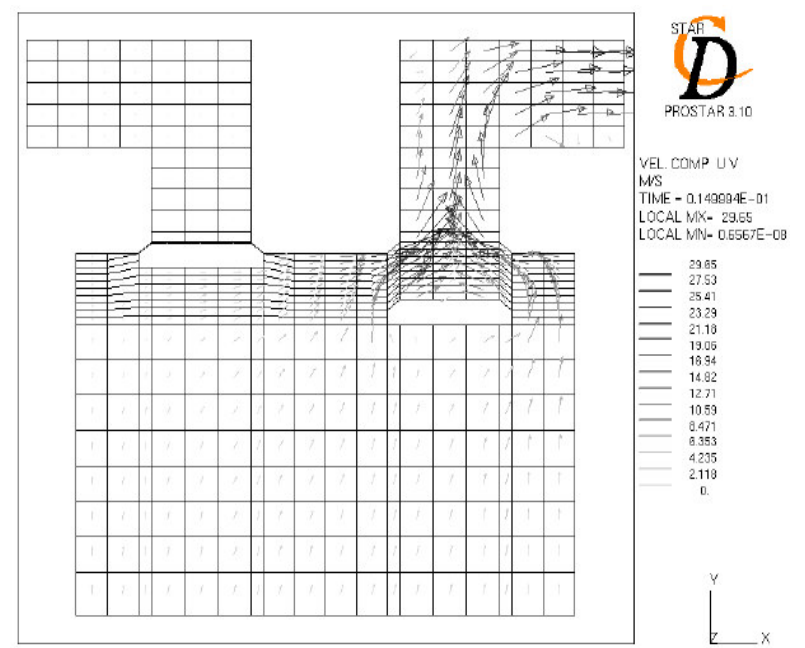

Fig. 12: Flow animation at exhaust valve 
Valve Lift Simulation: Whenever a simulation is run, GT-SUITE produces several output files that contain simulation results in various formats. Most of the output is available in the post-processing application GT-POST. GT-POST is powerful tool that can be used to view animation and order analysis output ${ }^{[2]}$. After the simulations are finished, report tables that summarize the simulations can be produced. These reports contain important information about the simulation and simulation result in a tabular form. The computational simulation of the engine model result is informed the engine performance.

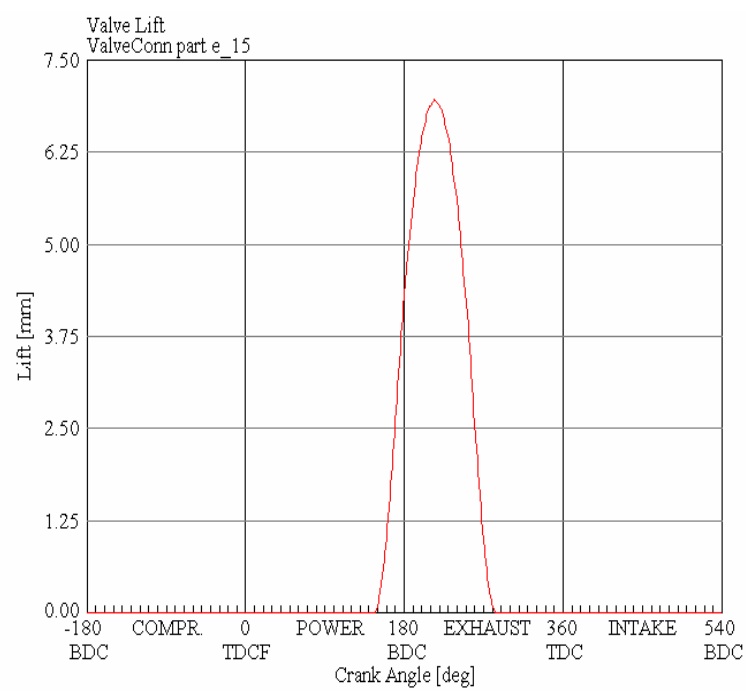

Fig. 13: Exhaust valve lift

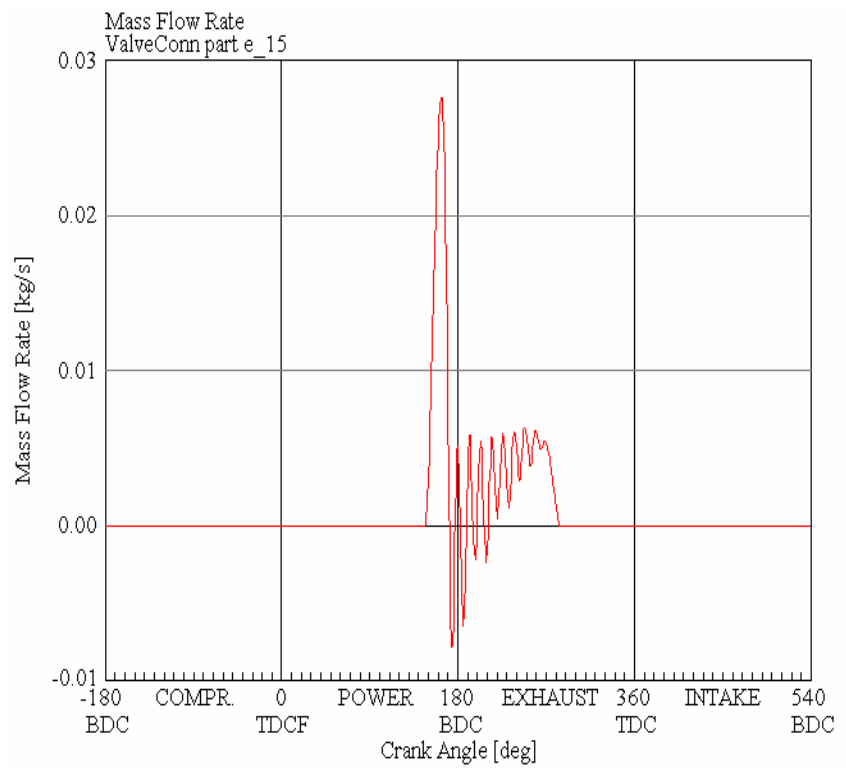

Fig. 14: Mass flow rate in exhaust valve

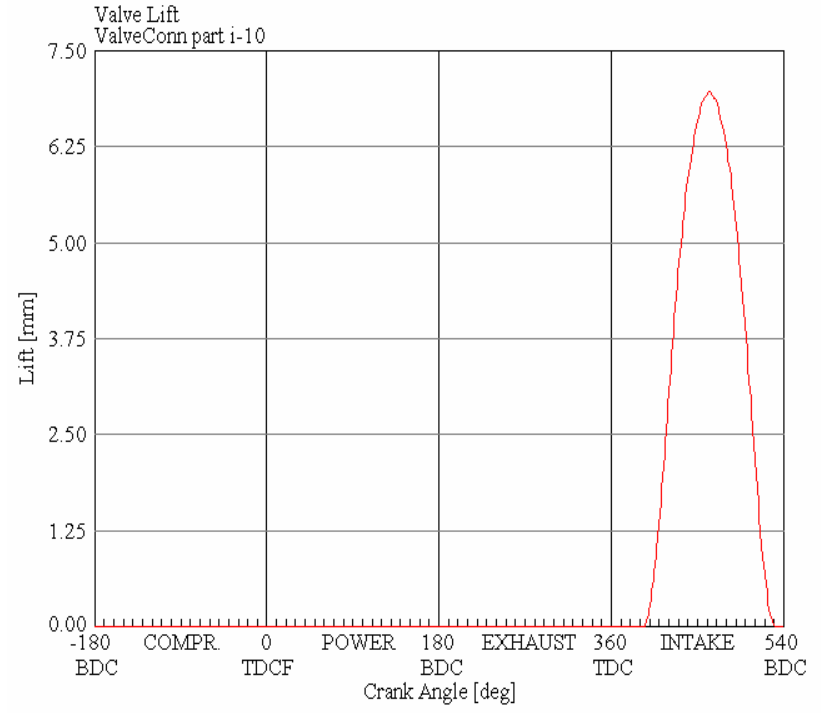

Fig. 15: Intake valve lift

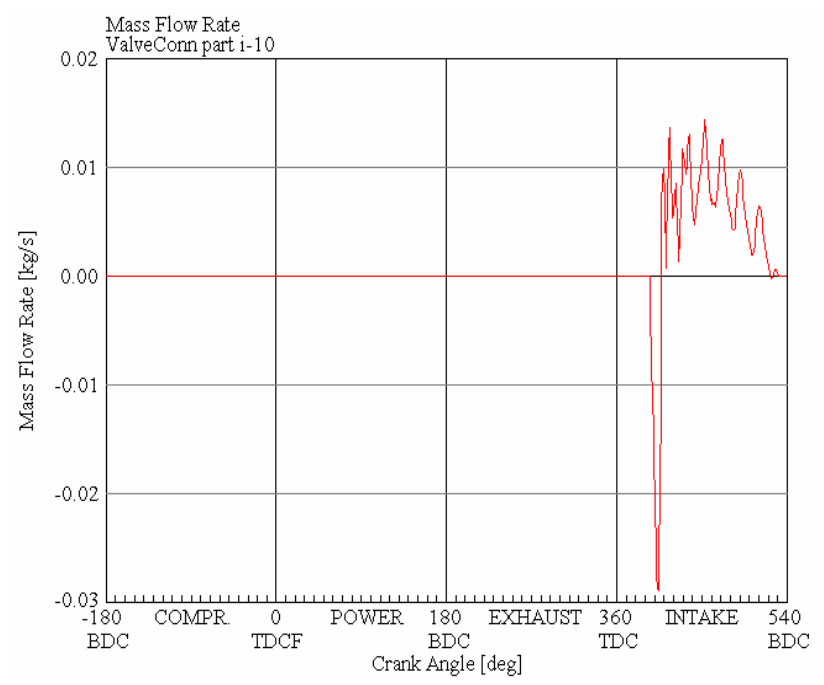

Fig. 16: Mass flow rate in intake valve

In the GT-POWER computational model the exhaust valve performance is shows in Fig. 13, in the engine model the exhaust valve open start from 147 on crank angle degree and close in 282 on crank angle degree. The maximum exhaust valve lift of the model is $7.095 \mathrm{~mm}$. The intake valve open shows in Fig. 15, the intake valve start from 395 on crank angle degree and close in 530 on crank angle degree. The maximum intake valve lift of the model is the same with exhaust valve lift $7.095 \mathrm{~mm}$. The mass flow rate performance of the intake valve and exhaust valve was shows in Fig. 14 and Fig. 16. The GT-POWER model simulation data output and figure of the intake and exhaust valve is the same with the original engine data. 


\section{CONCLUSION}

The result of the intake and exhaust stroke flow simulation in an engine cylinder shows that the simulation commences at bottom dead centre (BDC) and continues for a time interval corresponding to $720^{\circ}$ of crank revolution. Inert scalars with the physical properties of air are used to track the intake and exhaust stream through the exhaust induction strokes in engine cylinder. The port boundary pressures are held constant at ambient condition throughout the simulation. Mesh design in problems with a moving mesh and changing cell connectivity is dominated by the need to keep the dynamic parts of the grid simple so that they can be easily changed during the transient run. The formulation of mesh motion in such problems is divided into two conceptual steps. The first deals with connectivity changed which are defined by PROSTAR events. The second step is to specify the grid vertex positions as function of time by supplying a set of PROSTAR grid-manipulation commands to be executed at each time step.

The GT-POWER model was result the air flow of engine performance parameters, but to validate this result must be compare with the experiment or engine performance theoretically for future work.

\section{ACKNOWLEDGEMENTS}

We would like to acknowledge University Malaysia Pahang for providing the fellowship to support this research project.

\section{REFERENCES}

1. Heywood, J.B., 1998. Internal Combustion Engine Fundamentals. McGraw-Hill, Singapore.

2. Gamma Technologies, 2004. GT-POWER User's Manual 6.1, Gamma Technologies Inc.

3. Ramadhas, A.S., Jayaraj, S., Muraleedharan, C., 2006. Theoretical modeling and experimental studies on biodiesel-fueled engine. Renewable Energy 31, pp: 1813-1826.
4. Ghojel, Jamil., Honnery, Damon., Al-Khaleefi, Khaled., 2006. Performance, emissions and heat release characteristics of direct injection diesel engine operating on diesel oil emulsion, Applied Thermal Engineering 26, pp: 2132-2141.

5. Lapuerta, Magín.,et.al., 2006. Effect of the gas state equation on the thermodynamic diagnostic of diesel combustion, Applied Thermal Engineering 26, pp: 1492-1499.

6. Bakar, Rosli.A., Semin., Ismail, Abdul.R., 2007. The internal combustion engine diversification technology and fuel research for the future: A Review, Proceeding of AEESEAP Regional Symposium on Engineering Education, Kuala Lumpur, Malaysia, pp: 57-62.

7. Bakar, Rosli.A., Semin., Ismail, Abdul.R., 2007. Effect Of Engine Performance For Four-Stroke Diesel Engine Using Simulation, Proceeding The $5^{\text {th }}$ International Conference On Numerical Analysis in Engineering, Padang-West Sumatera, Indonesia.

8. Kowalewicz, Andrzej., 1984. Combustion System of High-Speed Piston I.C. Engines, Wydawnictwa Komunikacji i Lacznosci, Warszawa.

9. Stone. Richard., 1997. Introduction to Internal Combustion Engines-2 ${ }^{\text {nd }}$ Edition, SAE Inc.

10. Ganesan, V., 1999. Internal Combustion Engines $2^{\text {nd }}$ Edition, Tata McGraw-Hill, New Delhi.

11. Riegler, Udo. G., Bargende, Michael., 2002. Direct coupled 1D/3D-CFD-computation (GTPower/Star-CD) of the flow in the switch-over intake system of an 8- cylinder SI engine with external exhaust gas recirculation, SAE Technical Paper 2002-01-0901.

12. Adapco. CD, Group., 2002. Methodology STARCD VERSION 3.15A, Computational Dynamics Limited. 